\title{
Research on the Competitiveness of Crediting Rating Industry using PCA Method
}

\author{
Qi Feng, Menggang Li, Daqing Gong* \\ School of Economics \& Management, Beijing Jiaotong University (China) \\ 154401453@.qq.com,morganli@vip.sina.com,*Corresponding author gongtuipigua@163.com
}

Received: September 2014

Accepted: October 2014

\section{Abstract:}

Purpose: This study investigates the industry competitiveness problem, which plays an important role in crediting rating industry safety. Based on a comprehensive literatures review, we found that there is much room to improve regarding of competitiveness assessment in crediting rating industry.

Design/methodology/approach: In this study, we propose the PCA (Principal Component Analysis) method to illustrate the problems.

Findings: America and Canada's companies (such as S\&P and DBRS) take the leading place in credit rating industry, and Japan' agencies have made great progress in industry competition (such as JCR), while China' agencies are lagging behind (Such as CCXI).

Research limitations/implications: It requires multi-year data for analysis, but the empirical analysis is carried out based on one-year data instead of multi-year data.

Practical implications: The research can fill the gaps for credit rating industry safety research. And study findings and feasible suggestions are provided for academics and practitioners.

Originality/value: This paper puts forward the competitive indicators of credit rating industry, and indicators of cause and outcome are considered.

Keywords: industry security, industry competitiveness, crediting rating, PCA 


\section{Introduction}

In an economy dominated society, credit has played an important role in social development. Credit rating determines the cost of companies finance and restricts its survival and development space. Moreover, it affects a country's asset prices and the stability of its financial market. With decades of economic and financial development, financial products, institutions and even sovereign states have been included in the rating range. When rating agencies did make mistakes, these mistakes would have serious consequences for the financial sector (White, 2010). Not only economists, but also average citizens paid attention to the credit rating industry due to the subprime crisis (Jeon \& Lovo, 2013). As a consequence, it can be seen that an explosion of the literatures on the industry come into being. Therefore, credit rating industry, especially the industry competitiveness occupies the commanding position in controlling the capital markets. It is closely related with the financial speaking right and financial sovereignty of the country, what is more, the credit rating industry safety issues is primarily depending on the industry's own security. One country's crediting rating agencies (CRAs) panics that follow incapability or even insolvency, especially of large CRAs, can severely jeopardize economic stability and state security. Therefore, investors, even government urgently need a credit rating competitiveness indicator to help identify the financial status and operational competence of country. CRAs rank the credit-worthiness of a wide variety of investment opportunities (Selig, 2011). So Competitiveness assessment of crediting rating industry should be studied.

CRAs play an important role in financial markets. The information provided by rating agencies can help the user in their decision-making. So many researches focused on CRAs itself, not the industry, such as, Utzig (2010) thought the outbreak of financial crisis have the closing relation with the CRAs, which was acknowledged by policymakers, market participants, and agencies themselves. Rating standards were the important factors which can affect the rating results. Loose ratings were associated with higher default rates (Alp, 2013). Credit rating could provide financial entities with an assessment of credit worthiness, investment risk, and default probability (Chen \& Cheng, 2013). So investors placed too much faith in CRAs, and if CRAs failed, it was tempting to take the them out for a public whipping (Benmelech \& Dlugosz, 2010). Even CRAs should be under intense scrutiny by government investigations as a result of the wrong ways (Scalet \& Kelly, 2012). At the same time, some tactics are developed to solve the problem, such as, Hájek (2012) considered fuzzy logic method to enable users to model the meaning of natural language words in credit rating industry; Pagano and Volpin (2010) thought CRAs' underestimating the credit risk associated with structured credit products.

Sovereigns need ratings so that they can attract foreign investors, and CRAs can play import role in this process. Since early in the 20th century, CRAs had been dominated by a duopolyMoody's Investors Services, Inc. (Mood's) and standard \& Poor's Ratings Services (S\&P) (Coffee Jr, 2006). According to White (2010), there were around 150 CRAs, but the three 
largest competitors shared roughly 95 percent of the market. S\&P and Mood's had 40 percent of the market while Fitch Ratings holded 15 percent. Consequently, CRAs frequently provided different ratings for the same entity. Alsakka and Gwilym (2009) showed that rating disagreements across agencies are more frequent for sovereign ratings than for companies ratings. So CRAs were condemned for failing to predict crisis based on the sovereign rating activities and CRAs had also been criticized for responding with a considerable time lag, also on many other occasions (Haan \& Amtenbrink, 2011). While the striking fact about the credit rating industry was its persistent fewness of nincumbents (White, 2002), and the original incumbent such as Moody's or S\&P's had been in the market for long time and had demonstrated its ability. A new entrant can be skilled than the incumbent, but it had not yet been given opportunities to make rating and therefore to prove its expertise (Jeon \& Lovo, 2011). So the competitiveness assessment of credit rating industry is of most important for Sovereigns and they could make clear of their financial safety, even the sovereign safety.

Conflicts of interest, shifts in country's culture, and lack of regulatory oversight can exert an influence on the competitiveness assessment of credit rating industry. Currently, researches on the credit rating industry mostly focused on the interest conflicts of credit rating and regulatory system. So the research question in this study is: how to assess the overall development of credit rating industry quantitatively. At present, the aforementioned problems have not been resolved yet in related research works. This article will take a comprehensive assessment on credit rating industry based on PCA method, emphatically from the angle of competitiveness. The study is organized as follows: in the following section, it presents the indicators of cause and outcome. In section 3, it introduces the PCA method, which forms the theoretical foundation of this study. In section 4 , it takes empirical researches on credit rating industry competitiveness assessment, as well as the results through which we verify the model. Finally we conclude the whole study.

\section{The Indicators}

In the current time, scholars and organizations have two ways to analyze industry international competitiveness: firstly, the results of industry competitiveness; secondly, the factors affecting the industry competitiveness. Michael Porter's 'diamond system is served as the theoretical framework, then the indicators of industry competitiveness can be established, so we can take a detailed analysis and research on the competitiveness of the credit rating industry.

According to the principle of Delphi method (Table 1), we can identify the competitiveness index system of credit rating industry. The index system can be divided into three layers, which are shown in Table 2. 


\begin{tabular}{|c|c|c|c|c|}
\hline \multirow[b]{2}{*}{ Indicators } & \multicolumn{4}{|c|}{ Scoring criteria } \\
\hline & $\begin{array}{l}\text { ON } 25 \text { points } \\
\text { (not important) }\end{array}$ & $\begin{array}{l}\text { 25 50points } \\
\text { (common) }\end{array}$ & $\begin{array}{l}\text { 50 75points } \\
\text { (important) }\end{array}$ & $\begin{array}{l}75 \sim 100 \text { points } \\
\text { (very important) }\end{array}$ \\
\hline \multicolumn{5}{|l|}{ International market share } \\
\hline \multicolumn{5}{|l|}{ Industrial concentration } \\
\hline \multicolumn{5}{|l|}{ Scale growth } \\
\hline \multicolumn{5}{|l|}{ Revenue growth } \\
\hline \multicolumn{5}{|l|}{ Annual income } \\
\hline \multicolumn{5}{|l|}{$\begin{array}{l}\text { Proportion of international revenue to total } \\
\text { revenue }\end{array}$} \\
\hline \multicolumn{5}{|l|}{ Types of rating business } \\
\hline \multicolumn{5}{|l|}{ The number of analysts } \\
\hline \multicolumn{5}{|l|}{ The education of analysts } \\
\hline \multicolumn{5}{|l|}{ The qualifications Analysts } \\
\hline \multicolumn{5}{|l|}{ Database } \\
\hline \multicolumn{5}{|l|}{ Goodwill capital/total capital } \\
\hline \multicolumn{5}{|l|}{ Number of enterprises authorized by NRSRo } \\
\hline \multicolumn{5}{|l|}{ Default rate } \\
\hline \multicolumn{5}{|l|}{ The share of foreign stock equity } \\
\hline \multicolumn{5}{|l|}{ The market control rate by foreign equity } \\
\hline \multicolumn{5}{|l|}{ Technology dependence } \\
\hline \multicolumn{5}{|l|}{ The market control rate by own brands share } \\
\hline \multicolumn{5}{|l|}{ The support of industrial policies } \\
\hline \multicolumn{5}{|l|}{ The completeness of policies and regulations } \\
\hline \multicolumn{5}{|l|}{ The effectiveness of policies and regulations } \\
\hline \multicolumn{5}{|l|}{ The adequacy of government regulation } \\
\hline \multicolumn{5}{|l|}{ The feasibility of government regulation } \\
\hline The completeness of government regulation & & & & \\
\hline
\end{tabular}

(a) According to the economic implications of various indicators, the criteria is given $0-25,25-50,50-75,75-100$ four intervals to determine index score. The detailed results are shown in Table 2.

(b) Credit rating industry involves a wide range of indicators and related statistics are not comprehensive and are of different caliber. Not only can the scoring method improve the operability of model, but be used in industrial security management.

Table 1. Scoring Criteria

\begin{tabular}{|c|c|c|}
\hline \multirow{17}{*}{$\begin{array}{l}\text { Industry } \\
\text { competitiveness }\end{array}$} & \multirow{8}{*}{$\begin{array}{l}\text { Market } \\
\text { competitiveness }\end{array}$} & International market share \\
\hline & & Industrial concentration \\
\hline & & Scale growth \\
\hline & & Revenue growth \\
\hline & & Annual income \\
\hline & & Proportion of international revenue to total revenue \\
\hline & & The adequacy of government regulation \\
\hline & & The support of industrial policies \\
\hline & \multirow{5}{*}{$\begin{array}{l}\text { Technology } \\
\text { competitiveness }\end{array}$} & The education of analysts \\
\hline & & The number of analysts \\
\hline & & Types of rating business \\
\hline & & Technology dependence \\
\hline & & Database \\
\hline & \multirow{2}{*}{ Recognition } & Goodwill capital / total capital \\
\hline & & Number of enterprises authorized by NRSRo \\
\hline & \multirow{2}{*}{ Industrial control } & The share of foreign stock equity \\
\hline & & The market control rate by Foreign equity \\
\hline
\end{tabular}

Table 2. Indicator System 
The indicators of cause and outcome are included in the index system, which can fully explain the international competitiveness, company's competitiveness, product's competitiveness and environmental competitiveness of credit rating industry. And this index system takes the industrial properties into consideration.

\section{The Method}

A number of indicators should be taken into consideration so as to study the competitiveness of credit rating industry, but there are overlaps of information for these indicators. PCA method is a reduction to high-dimensional variable space under the principle of minimal loss of information; and the new linear combination can reflect the information of original, meanwhile, it can keep most of information of the original variations. Therefore, this paper uses PCA method to study the competitiveness of credit rating industry comprehensively.

\subsection{The Principle of PCA Method}

Assuming $n$ samples and each sample has $p$ variables, so a matrix of $n \times p$ is constituted:

$$
\mathbf{X}=\left[\begin{array}{cccc}
x_{11} & x_{12} & \cdots & x_{1 p} \\
x_{21} & x_{22} & \cdots & x_{2 p} \\
\cdots & \cdots & \cdots & \cdots \\
x_{n 1} & x_{n 2} & \cdots & x_{n p}
\end{array}\right]
$$

When $p$ is relatively large, it is difficult to calculate in $p$-dimensional space. To overcome this problem, it needs to reduce the dimensions. Consequently, fewer and comprehensive indexes are extracted from the original ones, and these independent indexes can reflect most of the information of original variables.

Definition: $x_{1}, x_{2}, \ldots, x_{p}$ is the original variables, $z_{1}, z_{2}, \ldots, z_{m}(m \leq p)$ is the new variables.

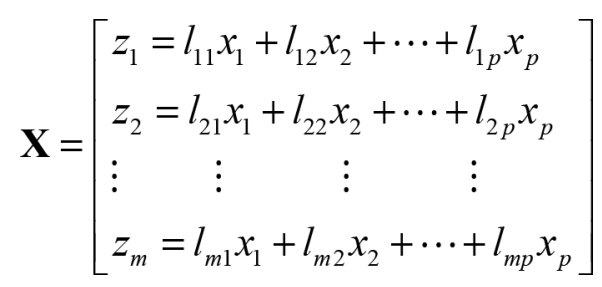




\section{Constrains:}

(a) $z_{i}$ is independent with $z_{i}(i \neq j ; i, j=1,2, \ldots, m)$;

(b) $z_{1}$ is the largest variance of a linear combination of $x_{1}, x_{2}, \ldots, x_{p} ; z_{2}$ is also the largest variance of a linear combination of $x_{1}, x_{2}, \ldots, x_{p}$; in the same way, $z_{m}$ is the largest variance of a linear combination of $x_{1}, x_{2}, \ldots, x_{p}$. So New variables $z_{1}, z_{2}, \ldots, z_{m}$ is the principal component.

Based on the analysis above, the essence of PCA method is to determine the original variables' $x_{j}(j=1,2,3, \ldots, p)$ loading $l_{i j}(i=1,2, \ldots, m ; j=1,2,3, \ldots, p)$ on the principal components $z_{i}(j=1,2,3, \ldots, m)$. The loadings are the corresponding eigenvectors of the eigenvalues.

\subsection{The Process of PCA Method}

(a) Firstly, coefficient matrix of indicators is got.

$$
R=\left[\begin{array}{cccc}
r_{11} & r_{12} & \cdots & r_{1 p} \\
r_{21} & r_{22} & \cdots & r_{2 p} \\
\cdots & \cdots & \cdots & \cdots \\
r_{p 1} & r_{p 2} & \cdots & r_{p p}
\end{array}\right]
$$

Where $r_{i j}(i, j=1,2,3, \ldots, p)$ is the correlation coefficient of original variables, and $r_{i j}=r_{j i}$. The formula is as follows:

$$
r_{i j}=\frac{\sum_{k=1}^{n}\left(x_{k i}-\overline{x_{i}}\right)\left(\mathrm{x}_{k j}-\overline{x_{j}}\right)}{\sqrt{\sum_{k=1}^{n}\left(x_{k i}-\overline{x_{i}}\right)^{2}\left(\mathrm{x}_{k j}-x_{j}\right)^{2}}}
$$

(b) Secondly, eigenvectors and eigenvalues of original variables are got. The details are as follows: $|\lambda I-R|=0$, so eigenvalues can be got based on Jacobi method, and $\lambda_{1} \geq \lambda_{2} \geq \cdots \geq \lambda_{p} \geq 0$; corresponding eigenvector $e_{i}(i=1,2,3, \ldots, p)$ of $\lambda_{i}$ can be got too, and $e_{i}=1, \sum_{i=1}^{p} e_{i j}^{2}=1$, where $e_{i j}$ is the $\mathrm{j}$-th component of vector $e_{i}$.

(c) Thirdly, the contribution rate and cumulative contribution rate of principal components are got. 
The contribution rate is

$$
b_{i}=\frac{\lambda_{i}}{\sum_{k=1}^{p} \lambda_{k}}(i=1,2,3, \cdots p)
$$

The cumulative contribution rate is

$$
\sum_{k=1}^{i} b_{k}=\frac{\sum_{k=1}^{i} \lambda_{k}}{\sum_{k=1}^{p} \lambda_{k}} \quad(i=1,2,3, \cdots p)
$$

The model is satisfying if the cumulative contribution rate can reach $90 \%$.

(d) Fourthly, the loadings of principal components are got. The loadings are

$$
l_{i j}=p\left(z_{i}, x_{j}\right)=\sqrt{\lambda_{i} e_{i j}} \quad(i, j=1,2, \cdots p)
$$

(e) At last, all the principal components can be calculated as follows:

$$
Z=\left[\begin{array}{cccc}
z_{11} & z_{12} & \cdots & z_{1 m} \\
z_{21} & z_{22} & \cdots & z_{2 m} \\
\cdots & \cdots & \cdots & \cdots \\
z_{n 1} & z_{n 2} & \cdots & z_{n m}
\end{array}\right]
$$

\section{The Empirical Research}

\subsection{The Samples}

All major CRAs locate in the financial markets more developed countries. The United States has the largest number of CRAs. Finance is one of the most important factors which can affect the credit rating market, that is, the demand of credit rating has closed relations with the development and prosperity of market. So there are great demands for credit rating in countries and regions of capital markets well developed, and these places have great advantage on the establishment and development of CARs (see Table 3). 


\begin{tabular}{|l|c|c|c|c|}
\hline The name of companies & Abbreviation & Country & Establishing date & Registration date in SEC \\
\hline Mood's Investor Sevices, Inc. & Mood's & USA & 1909 & 1975 \\
\hline Fitch, Inc. & Fitch & USA & 1922 & 1975 \\
\hline Standard \& Poor's Rating Sevices & S\&P & USA & 1923 & 1975 \\
\hline Canadian Bond Rating Sevice & CRBS & Canada & 1972 & 1 \\
\hline Thomson Bank Watch & Thom & USA & 1974 & 1991 \\
\hline Japanese Bond Rating Insititue & JBRI & Japan & 1975 & $/$ \\
\hline Dominion Bond Rating Sevice & DBRS & Canada & 1977 & 1990 \\
\hline IBCA, Ltd. & IBCA & UK & 1978 & 1982 \\
\hline Du \& Phelps Credit Rating Co. & Duff & USA & 1980 & $/$ \\
\hline Japan Credit Rating Agency, Ltd. & JCR & Japan & 1985 & 1985 \\
\hline Nippon Investor Sevice Inc. & NIS & Japan & $/$ \\
\hline
\end{tabular}

Table 3. The Establishing Date of Major CARs

In China, there are four CRAs of large-scale: DAGONG Global Credit Rating Co., Ltd., China Lianhe Credit Rating Co., Ltd., China ChengXin International Credit Rating Co., Ltd. (CCXI is the short name) and Shanghai Brilliance Credit Rating \& Investment Services Co., Ltd. At present, although there is a certain gap compared with the world-while major rating agencies, these four companies have made great progress in domestic rating market.

DBRS, JCR, S\&P and CCXI are served as the samples. Due to the convergence and confidentiality of raw data, this paper makes the raw data standardization using expert scoring method, consequently, the value of data can be converted into the internal $[0,1]$. The formula is as follows:

$$
\overline{x_{i}}=\frac{x_{i}-x_{\min }}{x_{\max }-x_{\min }}
$$

Where $x_{i}$ is the input, $x_{\min }$ is the minimum of input, $x_{\max }$ is the maximum of input, and standardization of data is seen in Table 4. 


\begin{tabular}{|l|l|l|l|l|}
\hline Indicators & DBRS & JCR & S\&P & CCXI \\
\hline Goodwill capital / total capital & 0 & 0.9646 & 1 & 0.6138 \\
\hline Number of enterprises authorized by NRSRo & 0.13836 & 0.19497 & 1 & 0 \\
\hline The education of analysts & 0.1869 & 0.8587 & 1 & 0 \\
\hline The number of analysts & 0.8 & 1 & 1 & 0 \\
\hline Types of rating business & 0.8506 & 0.9865 & 1 & 0 \\
\hline Technology dependence & 0.0417 & 0 & 1 & 0.0833 \\
\hline Database & 0 & 0.0881 & 0.1159 & 1 \\
\hline The market control rate by Foreign equity & 0.6407 & 0.8691 & 1 & 0 \\
\hline The share of foreign stock equity & 1 & 1 & 1 & 0 \\
\hline International market share & 1 & 0 & 0.1076 & 0.0609 \\
\hline Industrial concentration & 1 & 0.5299 & 0 \\
\hline Scale growth & 1 & 0.5392 & 0.5815 & 0.5189 \\
\hline Revenue growth & 0.883 & 0.4069 & 1 & 0 \\
\hline Annual income & 0.8869 & 0.0767 & 1 & 0 \\
\hline Proportion of international revenue to total revenue & 0.9654 & 0.9811 & 1 & 0 \\
\hline The adequacy of government regulation & 1 & 0 & 0.4271 & 0.7201 \\
\hline The support of industrial policies & 0.7 & 0.9 & 1 & 0 \\
\hline
\end{tabular}

Table 4. The Standardization of Data

\subsection{The First PCA Method}

(a) The analysis of industrial control

Two principal components are extracted for industrial control indicator, and the cumulative contribution rate of variance is $100 \%$, so the scores of principal components are shown in Table 5.

\begin{tabular}{|c|c|c|c|c|}
\hline & DBRS & JCR & S\&P & CCXI \\
\hline F11 & -0.50 & -0.28 & -0.70 & 1.48 \\
\hline F12 & -1.41 & 0.68 & 0.73 & 0.01 \\
\hline
\end{tabular}

Table 5. The Scores of Principal Components (1)

The variance contribution rate of two principal components is served as the weights, so the comprehensive assessment function is got as below:

$$
\mathrm{F} 1=0.48 * \mathrm{~F} 11+0.52 * \mathrm{~F} 12
$$


At last, the assessment value of industrial control indicator of four companies is seen in Table 6.

\begin{tabular}{|l|l|l|l|l|}
\hline & DBRS & JCR & S\&P & CCXI \\
\hline F1 & -0.97 & 0.22 & 0.04 & 0.72 \\
\hline
\end{tabular}

Table 6. The Assessment Value of Industry Control

(b) The analysis of recognition

Two principal components are extracted for recognition indicator, and the cumulative contribution rate of variance is $100 \%$, so the scores of principal components are shown in Table 7.

\begin{tabular}{|c|c|c|c|c|}
\hline & DBRS & JCR & S\&P & CCXI \\
\hline F21 & 0.37 & 0.18 & 0.88 & -1.43 \\
\hline F22 & 0.50 & 1.1 & 1.16 & -0.44 \\
\hline
\end{tabular}

Table 7. The Scores of Principal Component (2)

Similarly, the variance contribution rate of two principal components is served as the weights, so the comprehensive assessment function is got as below:

$$
\mathrm{F} 2=0.55 * \mathrm{~F} 21+0.45 * \mathrm{~F} 22
$$

At last, the assessment value of recognition indicator of four companies is seen in Table 8.

\begin{tabular}{|l|c|c|c|c|}
\hline & DBRS & JCR & S\&P & CCXI \\
\hline F2 & 0.43 & 0.59 & 1.01 & -0.98 \\
\hline
\end{tabular}

Table 8. The Assessment Value of Recognition

(c) The analysis of technology competitiveness

Only one principal component is extracted for technology competitiveness indicator, so the score of principal component is served as the assessment value (see it in Table 9).

\begin{tabular}{|l|l|l|l|l|}
\hline & DBRS & JCR & S\&P & CCXI \\
\hline F3 & 0.22 & 0.62 & 0.63 & -1.47 \\
\hline
\end{tabular}

Table 9. The Assessment Value of Technology Competitiveness 
(d) The analysis of market competitiveness

Two principal components are extracted for market competitiveness indicator, and the cumulative contribution rate of variance is $91.078 \%$, so the scores of principal components are shown in Table 10.

\begin{tabular}{|c|c|c|c|c|}
\hline & DBRS & JCR & S\&P & CCXI \\
\hline F41 & 1.32 & -1.03 & -0.42 & 0.12 \\
\hline F42 & 0.47 & 0.09 & 0.86 & -1.42 \\
\hline
\end{tabular}

Table 10. the Scores of Principal Component (3)

Similarly, the comprehensive assessment function is got as below:

$$
\mathrm{F} 4=0.52 * \mathrm{~F} 41+0.48 * \mathrm{~F} 42
$$

At last, the assessment value of market competitiveness indicator of four companies is seen in Table 11.

\begin{tabular}{|c|c|c|c|c|}
\hline & DBRS & JCR & S\&P & CCXI \\
\hline F4 & 0.91 & -0.49 & 0.19 & -0.62 \\
\hline
\end{tabular}

Table 11. The Assessment Value of Market Competitiveness

\subsection{The Second PCA Method}

Based on the conclusions above, the summary of assessment value is seen in Table 12.

\begin{tabular}{|c|c|c|c|c|}
\hline & DBRS & JCR & S\&P & CCXI \\
\hline F1 & -0.97 & 0.22 & 0.04 & 0.72 \\
\hline F2 & 0.43 & 0.59 & 1.01 & -0.98 \\
\hline F3 & 0.22 & 0.62 & 0.63 & -1.47 \\
\hline F4 & 0.91 & -0.49 & 0.19 & -0.62 \\
\hline
\end{tabular}

F1: Industrial control; F2: Recognition; F3: Technology competitiveness; F4: Market competitiveness

Table 12. The Summary of Assessment Value

Principal component can be extracted if its Eigenvalue is bigger than 1 . If one principal component is extracted, the cumulative contribution rate of variance is only $76.670 \%$. Since the variance of another principal component is over 0.5 , two principal components are 
reasonable for the analysis. So two principal components are extracted, and the cumulative contribution rate of variance is $98.615 \%$. The scores of principal components are shown in Table 13.

\begin{tabular}{|c|c|c|c|c|}
\hline & DBRS & JCR & S\&P & CCXI \\
\hline F51 & -0.16 & 0.74 & 0.78 & -1.35 \\
\hline F52 & 1.44 & -0.73 & -0.09 & -0.62 \\
\hline
\end{tabular}

Table 13. The Scores of Principal Component (4)

Similarly, the variance contribution rate of these principal components is served as the weights, so the comprehensive assessment function is got as below:

$$
\mathrm{F} 5=0.62 * \mathrm{~F} 51+0.38 * \mathrm{~F} 52
$$

Therefore, the assessment value of competitiveness of four companies is seen in Table 14.

\begin{tabular}{|c|c|c|c|c|}
\hline & DBRS & JCR & S\&P & CCXI \\
\hline F5 & 0.448 & 0.181 & 0.449 & -1.073 \\
\hline
\end{tabular}

Table 14. The Assessment Value of Competitiveness

\subsection{The Analysis of Results}

-2 and 0.6 of real number are introduced, which are normalized with the data in Table 14 , so normalized data of four companies are obtained (see it in Table 15).

\begin{tabular}{|c|c|c|c|c|}
\hline & DBRS & JCR & S\&P & CCXI \\
\hline F5 & 0.9415 & 0.8388 & 0.9419 & 0.3565 \\
\hline
\end{tabular}

Table 15. The Normalized Data of Four Companies

-2 is set to 0 point, 0.6 is set to 100 point, so the total score of four companies is got (see it in Table 16).

\begin{tabular}{|c|c|c|c|c|}
\hline & DBRS & JCR & S\&P & CCXI \\
\hline F5 & 94.15 & 83.88 & 94.19 & 35.65 \\
\hline
\end{tabular}

Table 16. Total Score of Four Companies 
In Table 16, it can be seen that Most of the CRAs in America and Europe, such as Mood's, Fitch and S\&P, take the leading place in competitiveness efficiency, and Japan' agencies has made great progress in industry competition, while it lags behind for China' agencies. The conclusions are consistent with Hu's research (2014).

In America, credit rating industry not only can promote the development of financial industry, bringing out the great influence on international financial markets, but has a decisive impact on the entire international community, owing the great voice on international economic development. In most of EU countries, rating business are carried out by the national central banks or commercial banks. So far, there are no independent and strengthful CRAs for the whole of Europe, and almost all of the institutions are controlled by Mood's, Fitch and S\&P.

Credit rating industry started relatively late in Asia, which is still in its infancy. Although these local CRAs are the leader in the industry, they lag behind with the major CRAs. Credit rating industry of Japan and South Korea is relatively mature compared with other Asia countries. At present, China's credit rating industry is still in the early stages of development, there are no CRAs which can become the authorized institution by NRSRO. And these CRAs are still competing on the domestic market.

\section{Conclusions}

Credit rating industry is an important industry in the national economy, it can affect the normal operation of economic relations directly, and the industrial voice will safeguard national interests and security in the global competition; meanwhile, credit rating industry safety issues is primarily dependent on the industry's own security, and industry security has closed relation with competitiveness.

In this paper, not only the indicators of outcome, but the indicators of cause, are taken into consideration for the competitiveness analysis, and PCA method is introduced. The study finds that the United States, Europe and Asia are the world's major three credit rating market, but the degree of development is quite different. In all, the conclusions can promote the sustained and healthy development of credit rating industry, and thus to safeguard national economic and financial security.

Of course, like all of the researches, this paper has certain limitations and deficiencies. It requires multi-year data for analysis, but the empirical analysis is carried out based on oneyear data instead of multi-year data. 


\section{Acknowledgements}

The study is supported by National Natural Science Foundation (71132008), the Fundamental Research Funds for the Central Universities (B12JB00280) and Beijing Municipal Science \& Technology Commission (Z121100000312093), we appreciate the support very much.

\section{References}

Alp, A. (2013). Structural Shifts in Credit Rating Standards. The Journal of Finance, 68(6), 2435-2470. http://dx.doi.org/10.1111/jofi.12070

Alsakka, R., \& Gwilym, O. ap (2009). Heterogeneity of Sovereign Rating Migrations in Emerging Countries. Emerging Markets Review, 10, 151-165.

http://dx.doi.org/10.1016/j.ememar.2008.12.001

Benmelech, E., \& Dlugosz, J. (2010). The Credit Rating Crisis. University of Chicago Press.

Chen, Y., \& Cheng, C. (2013). Hybrid Models based on Rough Set Classifiers for Setting Credit Rating Decision Rules in the Global Banking Industry. Knowledge-Based Systems, 39, 224239. http://dx.doi.org/10.1016/j.knosys.2012.11.004

Coffee Jr, J. (2006). Gatekeepers: the Professions and Companies Governance. Oxford university press.

Haan, J. de, \& Amtenbrink, F. (2011). Credit Rating Agencies. Working paper.

Hájek, P. (2012). Credit Rating Analysis Using Adaptive Fuzzy Rule-based Systems: An Industry-specific Approach. Central European Journal of Operations Research, 20(3), 421-434. http://dx.doi.org/10.1007/s10100-011-0229-0

Hu, J. (2014). A Study on Competitiveness Efficiency of Crediting Rating Industry using DEA. Journal of Interdisciplinary Mathematics, 17(2). http://dx.doi.org/10.1080/09720502.2014.935085

Jeon, D. \& Lovo, S. (2011). Natural Barrier to Entry in the Credit Rating Industry. Paris December 2010 Finance Meeting EUROFIDAI-AFFI.

Jeon, D., \& Lovo, S. (2013). Credit Rating Industry: a Helicopter Tour of Stylized Facts and Recent Theories. International Journal of Industrial Organization, 31(5), 643-651. http://dx.doi.org/10.1016/j.ijindorg.2013.02.004

Pagano, M., \& Volpin, P. (2010). Credit Ratings Failures and Policy Options. Economic Policy, 25(62), 403-431. http://dx.doi.org/10.1111/j.1468-0327.2010.00245.x 
Scalet, S., \& Kelly, T. (2012). The Ethics of Credit Rating Agencies: What Happened and the Way Forward. Journal of Business Ethics, 111(4), 477-490. http://dx.doi.org/10.1007/s10551-012$1212-y$

Selig, K. (2011). Greed, Negligence, or System Failure? Credit Rating Agencies and the Financial Crisis. Case Study. http://www.duke.edu/web/kenanethics/CaseStudies/Moodys.pdf

Utzig, S. (2010). The Financial Crisis and the Regulation of Credit Rating Agencies: a European Banking Perspective. Working paper.

White, L. (2010). Markets: the Credit Rating Agencies. The Journal of Economic Perspectives, 24(2), 211-226. http://dx.doi.org/10.1257/jep.24.2.211

Journal of Industrial Engineering and Management, 2014 (www.jiem.org)

Article's contents are provided on a Attribution-Non Commercial 3.0 Creative commons license. Readers are allowed to copy, distribute and communicate article's contents, provided the author's and Journal of Industrial Engineering and Management's names are included. It must not be used for commercial purposes. To see the complete license contents, please visit http://creativecommons.org/licenses/by-nc/3.0/. 